Research Article

\title{
Effect of Wheat Straw Ash on Fresh and Hardened Concrete Reinforced with Jute Fiber
}

\author{
Naraindas Bheel $\mathbb{D}^{1},{ }^{1}$ Samiullah Sohu, ${ }^{2}$ Paul Awoyera ${ }^{(D)},{ }^{3}$ Ashok Kumar, ${ }^{4}$ \\ Suhail Ahmed Abbasi, ${ }^{2}$ and Oladimeji B. Olalusi ${ }^{5}{ }^{5}$ \\ ${ }^{1}$ Department of Civil and Environmental Engineering, Universiti Teknologi PETRONAS, Bandar Seri Iskandar, Tronoh, \\ Perak 31750, Malaysia \\ ${ }^{2}$ Department of Civil Engineering, Quaid-e-Awam University of Engineering, Science \& Technology, Campus Larkana, \\ Nawabshah, Pakistan \\ ${ }^{3}$ Department of Civil Engineering, Covenant University, Ota, Nigeria \\ ${ }^{4}$ Department of Civil Engineering, College of Engineering and Technology, University of Sargodha, Sargodha, Pakistan \\ ${ }^{5}$ Department of Civil Engineering, University of KwaZulu-Natal, Durban, South Africa
}

Correspondence should be addressed to Naraindas Bheel; naraindas_20001014@utp.edu.my

Received 25 November 2020; Revised 25 December 2020; Accepted 30 December 2020; Published 15 January 2021

Academic Editor: Mehmet Serkan KIRGIZ

Copyright (c) 2021 Naraindas Bheel et al. This is an open access article distributed under the Creative Commons Attribution License, which permits unrestricted use, distribution, and reproduction in any medium, provided the original work is properly cited.

\begin{abstract}
In the present era, a number of researchers are using either industrial or agricultural priceless products as a basic source of raw materials for the construction industry. These waste products are economical and helpful in producing a sustainable environment and reducing environmental pollution, which is called handling waste products. However, this research work was conducted on concrete containing $0.25 \%, 0.50 \%, 0.75 \%$, and $1 \%$ of jute fiber as reinforcement material and $10 \%, 20 \%, 30 \%$, and $40 \%$ of wheat straw ash (WSA) as replacement for fine aggregates. Moreover, the separate and combined effect of jute fiber and WSA as a replacement for sand ingredient in concrete is to determine the fresh and hardened properties of concrete. In this research, a number of concrete samples were prepared with $1: 1.5: 3 \mathrm{mix}$ proportion at 0.54 water-cement ratio and cured at 28 days. The experimental outcomes displayed that the compressive, splitting tensile, and flexural strengths improved by $32.88 \mathrm{MPa}, 3.80 \mathrm{MPa}$, and $5.30 \mathrm{MPa}$ at $0.50 \%$ of jute fiber along with $30 \%$ of WSA at 28 days consistently. Similarly, the modulus of elasticity was developed while the dosages of jute fiber and WSA increased together in concrete. Moreover, the permeability and workability of concrete were reduced while utilized jute fiber and WSA increased together in concrete.
\end{abstract}

\section{Introduction}

Concrete is the main building material substantially used all over the world. Since its creation in the Roman era, its use in various industries has grown. This phenomenon is primarily explained by its superiority over other types of building materials in terms of compressive strength, durability, and efficiency [1]. However, some deficiencies occur in concrete due to weak in tensile strength, poor resistance to cracking, and low tendency to deformation and fracture in concrete. [2]. To recompense for the brittleness of conventional concrete, fiber-reinforced concrete is usually utilized as an alternative $[2,3]$. Moreover, the fiber is used in concrete as a reinforcement material from the Biblical era [4], and fibers are categorized into steel, glass, synthetic, carbon, and natural fibers, which have been incorporated into concrete to increase the tensile strength of concrete [5]. Among them, steel fiber is most extensively utilized in concrete $[4,6,7]$. However, steel fibers are susceptible to corrosion, which limits their use. To solve this problem, it is generally concluded that synthetic fibers are the alternative. However, the production of synthetic fibers is very expensive and energy consuming [8]. Under these conditions, natural fibers are generally considered a potential fiber replacement for the 
production of fiber-reinforced concrete. Natural fiberreinforced concrete is a cement-based concrete matrix in which natural fibers of discontinuous length are randomly distributed throughout the concrete matrix. Natural fiber has advantages in terms of the environment, economy, and energy and resource conservation [9]. In addition, it can reduce the use of concrete components (e.g., aggregates and cement) and, therefore, can contribute to sustainability.

According to the source of natural fibers, they are usually produced from three main sources such as plants, animals, and minerals [10]. Among them, plant fibers are preferred. Meanwhile, the animal fibers possess mainly protein and mineral fibers that are related to health problems, but cellulose is an essential element in plant fibers which makes it the most preferred one. With the exception of Pickering et al.'s study [10], these plant fibers have been shown to have higher strength and stiffness than animal fibers. Onuaguluchi and Banthia [9] also described the potential of plant fibers in concrete and reported that the performance of cementitious materials can be significantly improved by using natural plant fibers to improve the properties of cementitious materials. In addition, cellulose-based plant fibers can provide convenient reinforcement of cement-based concrete composites due to their low density [11], high tensile properties, and special microstructure.

The possibility of mixing different fibers such as jute, kenaf, hemp, coconut [12], and sisal in concrete has been studied to improve the characteristic strength of concrete. It was found that the addition of natural fibers in concrete can improve compressive strength, tensile strength, impact strength, cracking and impact resistance of concrete, fatigue strength, and impact resistance, as well as the strain capacity of concrete [12-15].

Another significant benefit of natural fiber is that it requires little energy to be produced [16]. Due to the good properties of synthetic fiber, using it in concrete improves the tensile properties of concrete. However, conventional synthetic fibers (such as steel and acrylic) are expensive and can increase the cost of the project. On the other hand, natural fibers represent a cheaper, environmental friendly, and sustainable solution to improve the tensile properties of concrete [12]. Hence, for this experimental study, jute fiber is used as the reinforcement ingredient in concrete. However, jute is one of the cheapest and strongest natural fibers widely used in Bangladesh [17]. Jute is the second largest textile fiber in the world, after cotton. Jute produced in Bangladesh accounts for $33 \%$ of its world production, and Bangladesh is the second-largest jute producer in the world [17]. Jute fiber is mainly composed of cellulose and plant lignin. As a natural fiber, jute has many inherent convenience properties such as high tensile strength, moderate fire resistance, biodegradability, renewability, recyclability, and environmental protection, making it more beneficial than other types of fibers $[17,18]$. In addition, natural sand is another main constituent of concrete used as fine aggregate that influences the natural resources. The maximum usage of river sand as fine aggregates which is derived from the river bed results in deterioration of the river bed, lower water table levels, erosion of the river bed, and destruction of the bridge structure, which causes unsustainable development of the country. Thus, finding possible alternatives to natural aggregates has become very essential and even more important. Besides, the continuous growth of agricultural and industrial waste is a major cause of a number of environmental problems, and this burden can be reduced by using wheat straw ash in concrete structures [19]. However, the use of agricultural ash such as WSA in concrete mixes is limited. In areas of mass production of WSA, the ability to use WSA as a specific component can provide a solution for managing this agricultural waste. Wheat provides the world's highest grain yield. Pakistan produces 27 million tons per year, making it the eighth largest wheat producer in the world. Pakistan produces large amounts of wheat straw as waste every year due to the high wheat harvest. For every kilogram of wheat grain produced, about $1.5 \mathrm{~kg}$ of wheat straw is obtained [20]. The high yield of wheat straw indicates that Pakistan produces about 16 million tons of wheat straw as waste annually. Traditionally, most of the straw produced in Pakistan has been disposed in open areas or burned outdoors. Thus, the improper handling of this waste leads to safety, health, and aesthetic problems. Therefore, the wheat straw ash is utilized as a replacement for sand ingredient in concrete. Although numerous experimental works were conducted on WSA as a replacement for cement in concrete [21-23], there is no research work performed on concrete with the inclusion of WSA as a replacement for sand ingredient. Besides, limited studies were conducted on jute fiber as reinforcement material in concrete. Furthermore, there is no any experimental work performed on concrete blended with the combined use of WSA as a replacement for sand ingredient and jute fiber as reinforcement constituents. Therefore, this research study is to determine the fresh (slump test) and hardened properties (i.e., compressive strength, tensile strength, flexural strength, modulus of elasticity, and water penetration depth) of concrete blended with the separate and combined usage of WSA as the replacement for sand ingredient and jute fiber as the volume fraction of concrete.

\section{Materials and Methods}

2.1. Materials. Wheat straw was collected from the Tando Jam region, Sindh, Pakistan. After collecting wheat straw, it was burnt under control temperature ranging from $500^{\circ} \mathrm{C}$ to $750^{\circ} \mathrm{C}$ for five hours to form ash. This ash was passed through a sieve of $4.75 \mathrm{~mm}$ in size, and then, it was utilized as a replacement for sand ingredient in concrete which possesses pozzolanic property. However, the sum of $\mathrm{SiO}_{2}, \mathrm{Al}_{2} \mathrm{O}_{3}$, and $\mathrm{Fe}_{2} \mathrm{O}_{3}$ is greater than $50 \%$ in any material which categorizes that the material has pozzolanic nature according to ASTM C618 [24] as shown in Table 1. Jute fiber is a natural fiber which is found abundantly in tropical regions. Jute fiber lengths vary from $10 \mathrm{~mm}$ to $20 \mathrm{~mm}$, and the diameter is $0.10 \mathrm{~mm}$. It is easily available and has high tensile strength. Moreover, the Portland cement (PC) was used for this research study as a binding component. The PC was obtained locally from Hyderabad, Pakistan. The chemical composition of PC and WSA is revealed in Table 1. In addition, river sand 
Table 1: Chemical composition of PC and WSA.

\begin{tabular}{lccccccccc}
\hline \multirow{2}{*}{ Binder } & \multicolumn{9}{c}{ Compound (\%) } \\
& $\mathrm{SiO}_{2}$ & $\mathrm{Al}_{2} \mathrm{O}_{3}$ & $\mathrm{Fe}_{2} \mathrm{O}_{3}$ & $\mathrm{CaO}$ & $\mathrm{Na}_{2} \mathrm{O}$ & $\mathrm{SO}_{3}$ & $\mathrm{MgO}$ & $\mathrm{K}_{2} \mathrm{O}$ & $\mathrm{P}_{2} \mathrm{O}_{5}$ \\
\hline PC & 20.78 & 5.11 & 3.17 & 60.22 & 0.18 & 2.86 & 3.00 & 0.39 & 0.26 \\
WSA & 67.83 & 6.44 & 4.36 & 10.60 & 0.47 & 1.85 & 1.78 & 5.43 & 1.24 \\
\hline
\end{tabular}

was applied as fine aggregates (FA) that passed from the \#4 sieve, and crushed stone was employed as coarse aggregates (CA) that were $20 \mathrm{~mm}$ in size. These materials were obtained locally from the region of Hyderabad, Sindh, Pakistan. The physical properties of the aggregates are mentioned in Table 2 . The sieve analysis of coarse and fine aggregates was performed by using ASTM C136 [25] as shown in Figure 1, and the bulk density of aggregates was calculated by observing ASTM C2997 [26]. Besides, the specific gravity and water absorption for fine and coarse aggregates were calculated under ASTM C128-93 [27] and ASTM C127-93 [28] correspondingly. Furthermore, drinking water was used for mixing and curing in the research study.

2.2. Mixture Design. The investigational procedure was implemented on the mixtures reinforced with $0.25 \%, 0.50 \%$, $0.75 \%$, and $1 \%$ of jute fiber as the volume fraction of concrete and $10 \%, 20 \%, 30 \%$, and $40 \%$ of WSA as the mass of fine aggregates individually and together in concrete to obtain the fresh and hardened properties of concrete. However, twenty-five concrete mixes were prepared with $1: 1.5: 3 \mathrm{mix}$ proportion at 0.54 water-cement ratio, in which one concrete mixture was made of PC only; four mixtures were equipped with the accumulation of $10 \%, 20 \%, 30 \%$, and $40 \%$ WSA as a replacement for sand ingredient, four concrete mixtures were made with the reinforcement of $0.25 \%, 0.50 \%$, $0.75 \%$, and $1 \%$ jute fiber as the volume fraction, and remaining sixteen concrete mixtures were prepared with the addition of $0.25 \%, 0.50 \%, 0.75 \%$, and $1 \%$ jute fiber along with $10 \%, 20 \%, 30 \%$, and $40 \%$ of WSA as a replacement for sand ingredient in concrete as indicated in Table 3.

\subsection{Testing Methods}

2.3.1. Slump Test. The slump test was performed on all concrete mixes with accumulation of various proportions of jute fiber, different percentages of WSA as a replacement for sand ingredient individually, and combined use in concrete under the ASTM C143-90 [29].

2.3.2. Hardened Properties of Concrete. Hardened properties of concrete such as compressive strength, splitting tensile strength, flexural strength, modulus of elasticity, and water penetration depth were obtained. However, cube samples $(100 \mathrm{~mm} \times 100 \mathrm{~mm} \times 100 \mathrm{~mm})$ were utilized for estimating the compressive strength of mixture reinforced with various percentages of jute fiber as the volume fraction and blended with different percentages of WSA as a replacement for sand ingredient separately and together in concrete by observing the ASTM C39/C39M [30], and cylinders $(200 \mathrm{~mm} \times 100 \mathrm{~mm})$ were utilized for splitting tensile strength of mixture reinforced with $0.25 \%, 0.50 \%$, $0.75 \%$, and $1 \%$ of jute fiber as the volume fraction of concrete and blended with $10 \%, 20 \%, 30 \%$, and $40 \%$ of WSA as the mass of fine aggregates individually and together in concrete by following the ASTM C 496-90 [31]. Similarly, the beam samples $(500 \mathrm{~mm} \times 100 \mathrm{~mm} \times 100 \mathrm{~mm})$ were cast for determining the flexural strength of mixture inclusion with various percentages of jute fiber as reinforcement material and addition of different percentages of WSA by the weight of fine aggregates separately and together in concrete under the ASTM C293/293M [32]. Moreover, the modulus of elasticity and permeability of mixture reinforced with various proportions of JF and several ratios of WSA as a replacement for sand ingredient separately and together in concrete were calculated by following ASTM C 469 [33] and BS EN 12390-8 [34], respectively. These tests were conducted at 28 days during curing.

\section{Results and Discussion}

Table 4 indicates the descriptive statistical data on experimental results in order to determine the range, mean, standard deviation, and coefficient of variation.

3.1. Slump Test. Figure 2 indicates the workability of concrete with the accumulation of $0.25 \%$ to $1 \%$ jute fiber as the volume fraction of concrete. The workability of green concrete was recorded as $46 \mathrm{~mm}, 37 \mathrm{~mm}, 29 \mathrm{~mm}$, and $20 \mathrm{~mm}$ at $0.25 \%, 0.50 \%, 0.75 \%$, and $1 \%$ of jute fiber which is less when compared to concrete without jute fiber. It was found that that the workability was reduced while the content of jute fiber increased in concrete. Such a phenomenon might be prompted by the large specific surface and the smaller diameter of the jute fiber when compared to other ingredients of concrete. On the other hand, the use of jute fiber is increased in concrete which absorbs more amount of water as compared to control mixture that results in reducing workability of concrete [9]. This remark is associated with Islam and Ahmed [18], where the workability of green concrete is minimized while the content of jute fiber improves. A similar trend was observed by Bheel et al. [35]. However, the workability of concrete intermingled with $10 \%$ to $40 \%$ of WSA as a replacement for sand in concrete as demonstrated in Figure 2. The slump was noted to be $20.68 \%, 36.21 \%, 50 \%$, and $65.52 \%$ at $10 \%, 20 \%, 30 \%$, and $40 \%$ of WSA which is smaller than that noted in plain concrete. It was observed that the slump of concrete is plummeted while the extent of WSA increases. Such a phenomenon of reduction in the slump is due to the large 
TABle 2: Physical properties of materials.

\begin{tabular}{lcccc}
\hline \multirow{2}{*}{ Materials } & & \multicolumn{2}{c}{ Physical properties of materials } \\
& Fineness modulus & Specific gravity & Bulk density (compacted) & Water absorption \\
\hline Fine aggregates & 2.15 & 2.61 & $1845 \mathrm{~kg} / \mathrm{m}^{3}$ & $1.3 \%$ \\
Coarse aggregates & 6.75 & 2.65 & $1630 \mathrm{~kg} / \mathrm{m}^{3}$ & $0.75 \%$ \\
Wheat straw ash & 7.80 & 2.21 & ----- & ----- \\
Cement & 5.60 & 3.15 & ---- & ---- \\
\hline
\end{tabular}

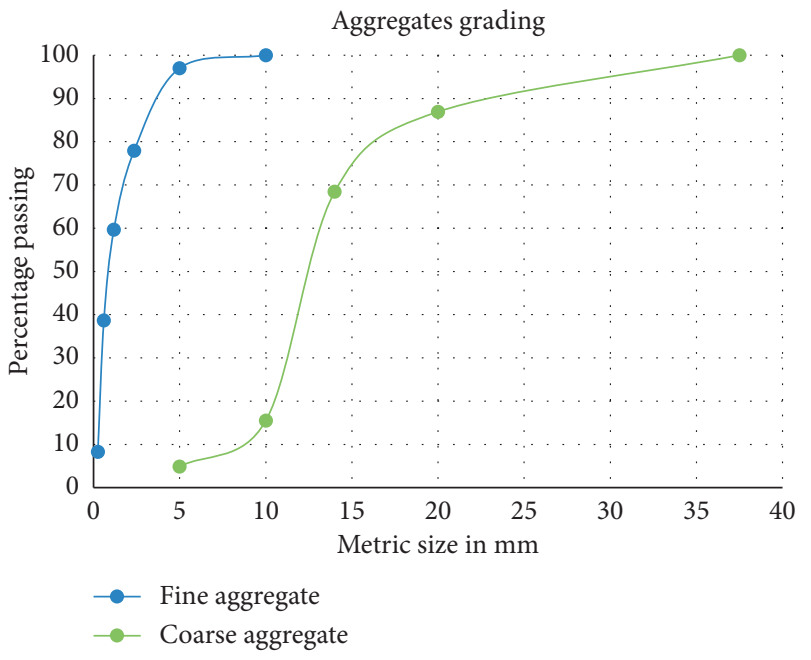

FIgURE 1: Sieve analysis for aggregates.

TABle 3: Mix proportion for concrete.

\begin{tabular}{|c|c|c|c|c|c|c|c|}
\hline Mix proportion & Mix ratio of concrete & Cement (\%) & $\begin{array}{c}\text { Wheat } \\
\text { straw ash (\%) }\end{array}$ & Fine aggregates (\%) & $\begin{array}{c}\text { Jute } \\
\text { fiber (\%) }\end{array}$ & $\begin{array}{c}\text { Coarse } \\
\text { aggregates (\%) }\end{array}$ & Water/binder ratio \\
\hline $\mathrm{C}$ & $1: 1.5: 3$ & 100 & 0 & 100 & 0 & 100 & 0.54 \\
\hline JF0.25 & $1: 1.5: 3$ & 100 & 0 & 100 & 0.25 & 100 & 0.54 \\
\hline JF0.50 & $1: 1.5: 3$ & 100 & 0 & 100 & 0.50 & 100 & 0.54 \\
\hline JF0.75 & $1: 1.5: 3$ & 100 & 0 & 100 & 0.75 & 100 & 0.54 \\
\hline JF1 & $1: 1.5: 3$ & 100 & 0 & 100 & 1 & 100 & 0.54 \\
\hline WSA10 & $1: 1.5: 3$ & 100 & 10 & 90 & 0 & 100 & 0.54 \\
\hline WSA20 & $1: 1.5: 3$ & 100 & 20 & 80 & 0 & 100 & 0.54 \\
\hline WSA30 & $1: 1.5: 3$ & 100 & 30 & 70 & 0 & 100 & 0.54 \\
\hline WSA40 & $1: 1.5: 3$ & 100 & 40 & 60 & 0 & 100 & 0.54 \\
\hline JF0.25WSA 10 & $1: 1.5: 3$ & 100 & 10 & 90 & 0.25 & 100 & 0.54 \\
\hline JF0.25WSA20 & $1: 1.5: 3$ & 100 & 20 & 80 & 0.25 & 100 & 0.54 \\
\hline JF0.25WSA30 & $1: 1.5: 3$ & 100 & 30 & 70 & 0.25 & 100 & 0.54 \\
\hline JF0.25WSA40 & $1: 1.5: 3$ & 100 & 40 & 60 & 0.25 & 100 & 0.54 \\
\hline JF0.5WSA10 & $1: 1.5: 3$ & 100 & 10 & 90 & 0.50 & 100 & 0.54 \\
\hline JF0.50WSA20 & $1: 1.5: 3$ & 100 & 20 & 80 & 0.50 & 100 & 0.54 \\
\hline JF0.50WSA30 & $1: 1.5: 3$ & 100 & 30 & 70 & 0.50 & 100 & 0.54 \\
\hline JF0.50WSA40 & $1: 1.5: 3$ & 100 & 40 & 60 & 0.50 & 100 & 0.54 \\
\hline JF0.75WSA 10 & $1: 1.5: 3$ & 100 & 10 & 90 & 0.75 & 100 & 0.54 \\
\hline JF0.75WSA20 & $1: 1.5: 3$ & 100 & 20 & 80 & 0.75 & 100 & 0.54 \\
\hline JF0.75WSA30 & $1: 1.5: 3$ & 100 & 30 & 70 & 0.75 & 100 & 0.54 \\
\hline JF0.75WSA40 & $1: 1.5: 3$ & 100 & 40 & 60 & 0.75 & 100 & 0.54 \\
\hline JF1WSA10 & $1: 1.5: 3$ & 100 & 10 & 90 & 1 & 100 & 0.54 \\
\hline JF1WSA20 & $1: 1.5: 3$ & 100 & 20 & 80 & 1 & 100 & 0.54 \\
\hline JF1WSA30 & $1: 1.5: 3$ & 100 & 30 & 70 & 1 & 100 & 0.54 \\
\hline JF1WSA40 & $1: 1.5: 3$ & 100 & 40 & 60 & 1 & 100 & 0.54 \\
\hline
\end{tabular}


TABLe 4: Descriptive statistical data on experimental results.

\begin{tabular}{|c|c|c|c|c|c|c|}
\hline & Slump (mm) & $\begin{array}{c}\text { Compressive } \\
\text { strength }(\mathrm{MPa})\end{array}$ & Tensile strength (MPa) & $\begin{array}{c}\text { Flexural } \\
\text { strength }(\mathrm{MPa})\end{array}$ & $\begin{array}{c}\text { Modulus of } \\
\text { elasticity }(\mathrm{GPa})\end{array}$ & $\begin{array}{c}\text { Permeability } \\
(\mathrm{mm})\end{array}$ \\
\hline Number of values & 25 & 25 & 25 & 25 & 25 & 25 \\
\hline Minimum & 12.00 & 28.00 & 3.100 & 4.300 & 26.50 & 7.000 \\
\hline Maximum & 58.00 & 32.88 & 3.800 & 5.300 & 31.45 & 22.00 \\
\hline Range & 46.00 & 4.880 & 0.7000 & 1.000 & 4.950 & 15.00 \\
\hline Mean & 31.52 & 30.70 & 3.473 & 4.844 & 29.30 & 14.32 \\
\hline Std. deviation & 11.74 & 1.261 & 0.1564 & 0.2299 & 1.377 & 3.637 \\
\hline Std. error of mean & 2.348 & 0.2522 & 0.03128 & 0.04597 & 0.2754 & 0.7274 \\
\hline Coefficient of variation & $37.25 \%$ & $4.108 \%$ & $4.503 \%$ & $4.746 \%$ & $4.699 \%$ & $25.40 \%$ \\
\hline
\end{tabular}

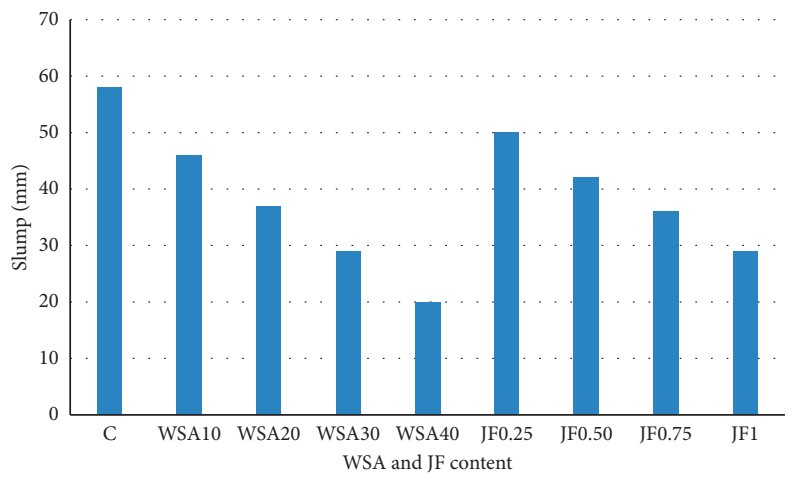

FIGURE 2: Workability of mixtures containing WSA and jute fiber.

specific surface area of WSA as constrained to cement which absorbs a high amount of water than PC. This opinion was in agreement with that of Bheel et al. [36] that the workability of fresh concrete is reduced as the extent of WSA as cementitious component increases. A similar trend was detected by Bheel et al. [37] and Dayo et al. [38]. Moreover, it was indicated in Figure 3 where the slump of concrete reinforced with $0.25 \%$ to $1 \%$ of jute fiber as volume fraction along with $10 \%$ to $40 \%$ of WSA as fine aggregate replacement. The optimum slump was noted as $58 \mathrm{~mm}$ at $0 \%$ of jute fiber and $0 \%$ of WSA, and the lowest slump was measured as $12 \mathrm{~mm}$ at $1 \%$ of jute fiber and $40 \%$ of WSA as fine aggregate replacement. It was noted that the slump drops as the dosages of jute fiber and WSA increase in concrete. This phenomenon of workability is reduced owing to large specific surface area of WSA and jute fiber which absorb some amount of water. This opinion was in agreement with Keerio et al. [39] that the workability decreases while the extent of glass powder as the replacement for sand along with silica fume as the replacement for cement component improve in concrete.

3.2. Compressive Strength. Figure 4 displays the compressive strength of the mixture containing $0.25 \%$ to $1 \%$ of jute fiber as the reinforcement ingredient at 28 days. It was improved by $31.5 \mathrm{MPa}$ which is $10.14 \%$ greater than that in plain concrete at $0.50 \%$ of jute fiber and the lowest strength was estimated as $28 \mathrm{MPa}$ that is $2.1 \%$ lower than the control mix at $1 \%$ of jute fiber as the reinforcement ingredient in

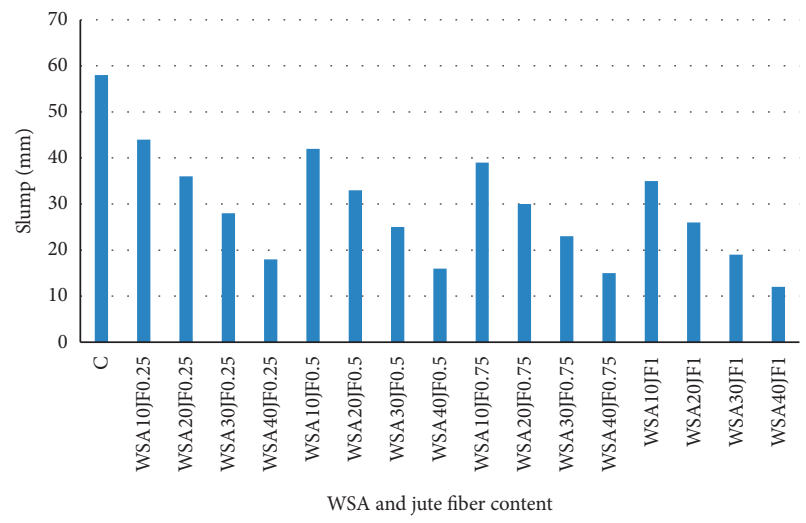

FIgURE 3: Workability of mixtures containing WSA and jute fiber.

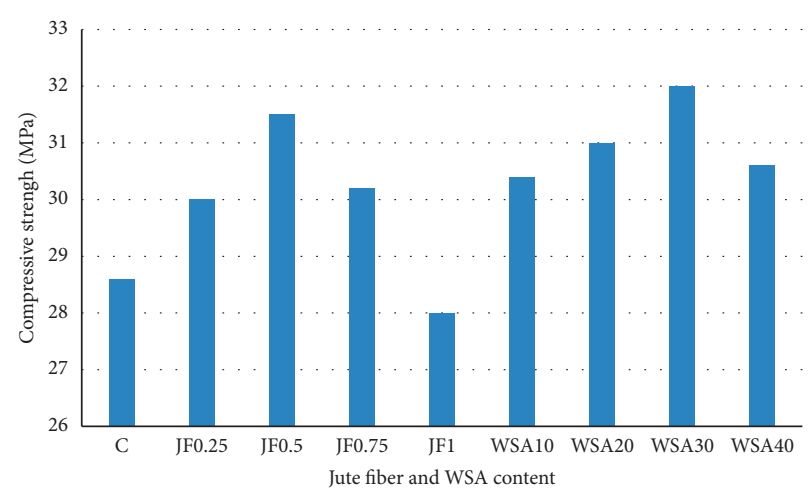

FIGURE 4: Compressive strength of mixture containing jute fiber and WSA.

concrete at 28 days correspondingly. The outcome suggested that the strength was enhanced while utilizing jute fiber up to $0.50 \%$ as reinforcement components and with further addition of jute fiber in concrete; the strength reduces due to the maximum number of voids generated by jute fiber addition which is greater than the optimum level of voids produced in concrete. This trend was observed by Zarakia et al. [40]. Islam and Ahmed [18] stated that the compressive strength was reduced while utilizing jute fiber beyond $0.50 \%$ as the reinforcement ingredient in concrete. However, the compressive strength of mixture with the introduction of $10 \%$ to $40 \%$ of WSA as the replacement of sand in concrete is 
recorded at 28 days as shown in Figure 4 . The optimum strength is recorded as $32 \mathrm{MPa}$ at $30 \%$ of WSA, and the minimum strength is calculated as $30.60 \mathrm{MPa}$ while utilizing $40 \%$ of WSA as the replacement for sand ingredient in concrete at 28 days correspondingly. It was noteworthy that the inclusion of WSA in concrete up to $30 \%$ that results in improving the strength can be indorsed to its voids-filling influence coupled with the potential pozzolanic reaction of the WSA, and then, the further addition of WSA causes reduction in compressive strength due to the dilution effect of the WSA that results in lower calcium hydroxide existing for product development [36]. This statement is similar to that by Kanaka and Thiyagarajan [41] and Bajad, Modhera, and Desai [42]. Keerio et al. [39] indicated that the strength is enhanced with increasing extent of glass powder equal to $30 \%$ as the sand substitute at 28 days. Figure 5 shows the compressive strength of the mixture with the introduction of $0.25 \%$ to $1 \%$ jute fiber and $10 \%$ to $40 \%$ of WSA as the replacement for sand ingredient at 28 days. The maximum compressive strength was calculated as $32.88 \mathrm{MPa}$ at $0.50 \%$ of jute fiber along with $30 \%$ of WSA, and the lowest strength was estimated as $28 \mathrm{MPa}$ while utilizing $1 \%$ of jute fiber along with $40 \%$ of WSA as the replacement for sand ingredient at 28 days correspondingly. It was observed that the strength was enhanced while utilizing jute fiber equal to $0.50 \%$ and WSA equal to $30 \%$ together because the fiberassociated influence stops transverse distortion resulting in increase in compressive strength [43]. Furthermore, accumulation of fiber at a greater rate causes more voids in concrete that results in reduction of compressive strength [44].

3.3. Splitting Tensile Strength of Concrete. Figure 6 indicates the splitting tensile strength of mixture containing $0.25 \%$ to $1 \%$ of jute fiber as the reinforcement ingredient at 28 days. It is improved by $3.60 \mathrm{MPa}$ at $0.50 \%$ of jute fiber which is $12.50 \%$ greater than that in plain concrete, and the lowest strength is estimated as $3.10 \mathrm{MPa}$ at $1 \%$ of jute fiber as the reinforcement ingredient in concrete that is $3.1 \%$ lower than in control mix at 28 days correspondingly. The outcome showed that the splitting tensile strength was enhanced while utilizing jute fiber equal to $0.50 \%$ as the reinforcement component and with further addition, it reduces due to increase in the amount of jute fiber which produces the voids in concrete. Besides, jute fibers can stop the spread of microcracks and finally improve the splitting tensile strength of the mixture. This trend was observed by Islam and Ahmed [18], where the indirect tensile strength was reduced while utilizing jute fiber beyond $0.50 \%$ as the reinforcement ingredient in concrete. The indirect tensile strength of concrete mix with the introduction of $10 \%$ to $40 \%$ of WSA as the replacement of sand in concrete obtained at 28 days is shown in Figure 6. The optimum strength was recorded as $3.50 \mathrm{MPa}$ at $30 \%$ of WSA, and the minimum strength was calculated by $3.35 \mathrm{MPa}$ while utilizing $40 \%$ of WSA as the replacement for sand ingredient in concrete at 28 days correspondingly. It was noteworthy that the inclusion of up to $30 \%$ WSA in concrete that results in increase in the strength may be

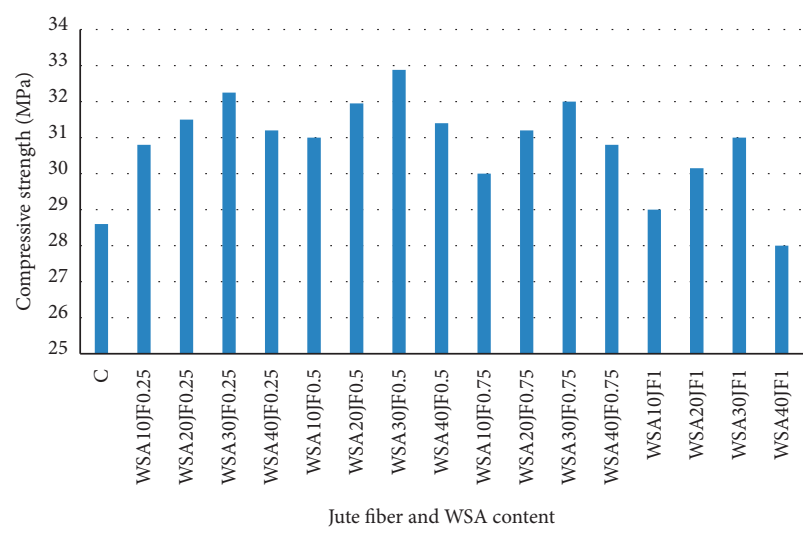

FIGURE 5: Compressive strength of mxture containing jute fiber and WSA.

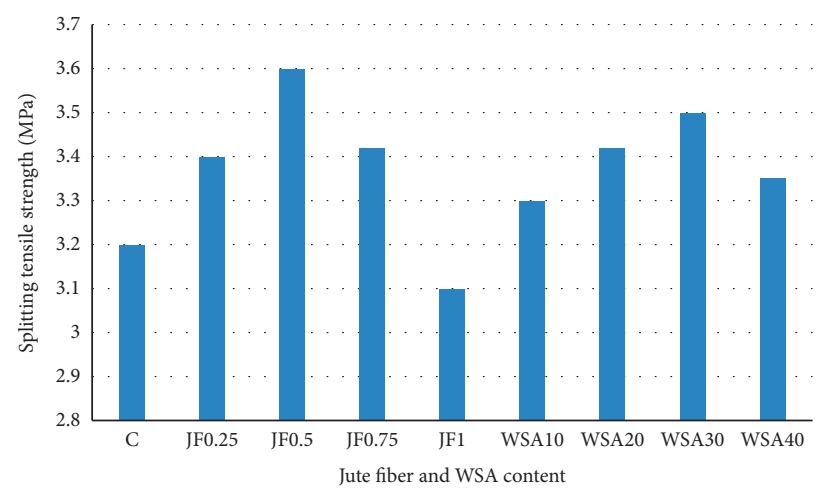

FIGURE 6: Splitting tensile strength of mixture containing jute fiber and WSA.

because specific surface area of WSA is higher than that of other components of concrete and further addition of WSA can cause reduction in splitting tensile strength. This statement is similar to that of Bheel et al. [36] that the strength was enhanced with increase in the extent of WSA equal to $10 \%$ as the cement substitute at 28 days. A similar trend is observed by Keerio et al. [39]. Also, Figure 7 shows the splitting tensile strength of concrete with the introduction of $0.25 \%$ to $1 \%$ jute fiber and $10 \%$ to $40 \%$ of WSA as the replacement for sand ingredient at 28 days. The maximum splitting tensile strength was measured as $3.80 \mathrm{MPa}$ at $0.50 \%$ of jute fiber along with $30 \%$ of WSA, and the lowest strength was estimated as $3.36 \mathrm{MPa}$ while utilizing $1 \%$ of jute fiber along with $40 \%$ of WSA as the replacement for sand ingredient at 28 days correspondingly. It was observed that the strength was enhanced while utilizing jute fiber up to $0.50 \%$ and WSA equal to $30 \%$ together in concrete. This opinion was in agreement with that of Bheel et al. [36] that the tensile strength was enhanced as the increase in the extent of WSA equal to $10 \%$ as the cementitious constituent in concrete. This similar trend was observed by Bheel et al. [45, 46].

3.4. Flexural Strength. Figure 8 shows the flexural strength of mixture containing $0.25 \%$ to $1 \%$ of jute fiber as the reinforcement ingredient at 28 days. The flexural strength was 


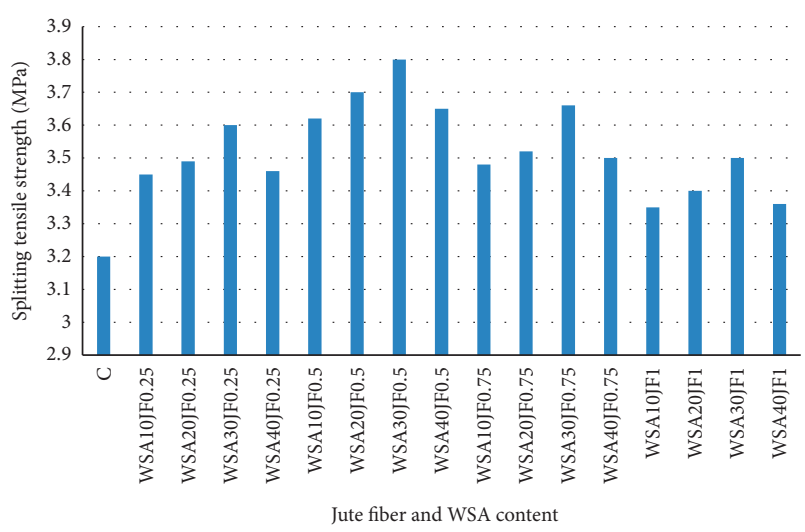

Figure 7: Splitting tensile strength of mixture containing jute fiber and WSA.

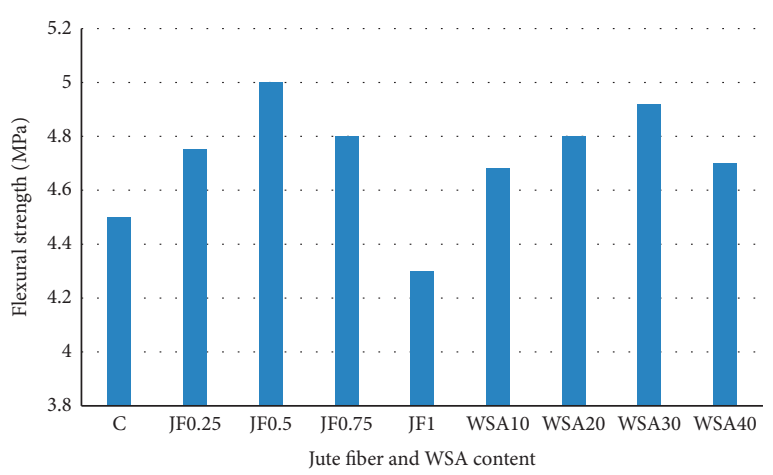

Figure 8: Flexural strength of mixture containing jute fiber and WSA.

improved by $5.0 \mathrm{MPa}$ which is $11.11 \%$ greater than that in plain concrete at $0.50 \%$ of jute fiber, and the lowest strength was estimated as $4.30 \mathrm{MPa}$ that is $4.44 \%$ lower than in the control mix at $1 \%$ of jute fiber as the reinforcement ingredient in concrete at 28 days correspondingly. The outcome of this study indicated that the flexural strength is enhanced while utilizing jute fiber up to $0.50 \%$ as the reinforcement component and with further addition of jute fiber, the flexural strength is reduced due to the increase in the amount of jute fiber which produces more voids in concrete. This trend was observed by Islam and Ahmed [18] that the flexural strength was reduced while utilizing jute fiber beyond $0.50 \%$ as the reinforcement ingredient in concrete. The flexural strength of the mixture with the introduction of $10 \%$ to $40 \%$ of WSA as the replacement of sand in concrete at 28 days is shown in Figure 8 . The optimum flexural strength was recorded as $4.92 \mathrm{MPa}$ at $30 \%$ of WSA, and the minimum flexural strength was calculated as 4.70 MPa while utilizing $40 \%$ of WSA as the replacement for sand ingredient in concrete at 28 days correspondingly. It was noteworthy that the inclusion of WSA in concrete up to $30 \%$ that results in increase in the flexural strength may be associated to the high dosage of silica, aluminum oxide, and iron oxide in WSA and further addition of WSA can cause reduction in the flexural strength owing to its slow pozzolanic reaction. This statement is in agreement with that of Bheel et al. [36] that the strength was enhanced with an incline in the extent of wheat straw ash equal to $10 \%$ as the sand substitute at 28 days. A similar trend was observed by Dayo et al. [47] and Bheel et al. [48]. Figure 9 shows the flexural strength of concrete with the introduction of $0.25 \%$ to $1 \%$ jute fiber and $10 \%$ to $40 \%$ of WSA as the replacement for sand ingredient at 28 days. The maximum flexural strength was measured as $5.30 \mathrm{MPa}$ at $0.50 \%$ of jute fiber along with $30 \%$ of WSA, and the lowest strength was estimated as $4.40 \mathrm{MPa}$ while utilizing $1 \%$ of jute fiber along with $40 \%$ of WSA as the replacement for sand ingredient at 28 days correspondingly. It was observed that the flexural strength was enhanced while utilizing jute fiber up to $0.50 \%$ and WSA equal to $30 \%$ together in concrete. This opinion was in agreement with that of Bheel et al. [45] that the flexural strength was enhanced as the extent of metakaolin and GGBFS equal to $10 \%$ as the binary cementitious component in concrete improved.

3.5. Modulus of Elasticity. Figure 10 shows the modulus of elasticity of concrete containing $0.25 \%$ to $1 \%$ of jute fiber as the reinforcement ingredient at 28 days. The modulus of elasticity of concrete is measured as $27.15 \mathrm{GPa}, 28.50 \mathrm{GPa}$, $29.25 \mathrm{GPa}$, and $30.45 \mathrm{GPa}$ at $0.25 \%, 0.5 \%, 0.75 \%$, and $1 \%$ of jute fiber which is higher than that of plain concrete at 28 days, respectively. The outcome shows that the modulus of elasticity of concrete is enhanced while utilizing jute fiber as the reinforcement component in concrete to form harder one as compared to plain concrete. A similar investigational study was performed by Bheel et al. [35] that the modulus of elasticity is increased with the growth in the extent of human hair fiber at 90 days. The modulus of elasticity of mixture is determined with addition of $10 \%$ to $40 \%$ of WSA as the replacement of sand in concrete at 28 days as shown in Figure 10. The modulus of elasticity of concrete is recorded as $27.10 \mathrm{GPa}, 28.30 \mathrm{GPa}, 29.40 \mathrm{GPa}$, and $30.35 \mathrm{GPa}$ at $10 \%, 20 \%, 30 \%$, and $40 \%$ of WSA as the replacement for sand ingredient which is higher than that in plain concrete at 28 days correspondingly. It is noted that the inclusion of the WSA content in concrete results in increase in the modulus of elasticity. This aspect is observed by Foong et al. [49] that the modulus of elasticity of concrete is enhanced while utilizing rice husk ash equal to $15 \%$ as the cementitious material at 28 days. Figure 11 shows that the modulus of elasticity of concrete is calculated with inclusion of $0.25 \%$ to $1 \%$ jute fiber and $10 \%$ to $40 \%$ of WSA as the replacement for sand ingredient at 28 days. The maximum modulus of elasticity is measured as $31.45 \mathrm{GPa} \mathrm{mm}$ at $1 \%$ of jute fiber along with $40 \%$ of WSA, and the lowest modulus of elasticity is estimated at 26.50 GPa while utilizing $0 \%$ of jute fiber along with $0 \%$ of WSA as the replacement for the sand ingredient at 28 days, respectively. It is noted that the modulus of elasticity is increasing with increase in jute fiber and WSA content together in concrete. This opinion was in agreement with that of Bheel et al. [36] that the modulus of elasticity was inclined as the extent of wheat straw ash as the 


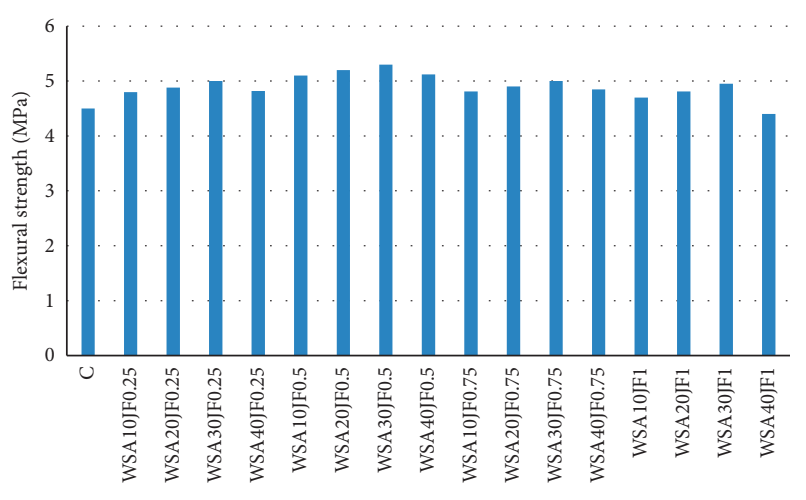

Jute fiber and WSA content

FIGURE 9: Flexural strength of mixture containing WSA and jute fiber.

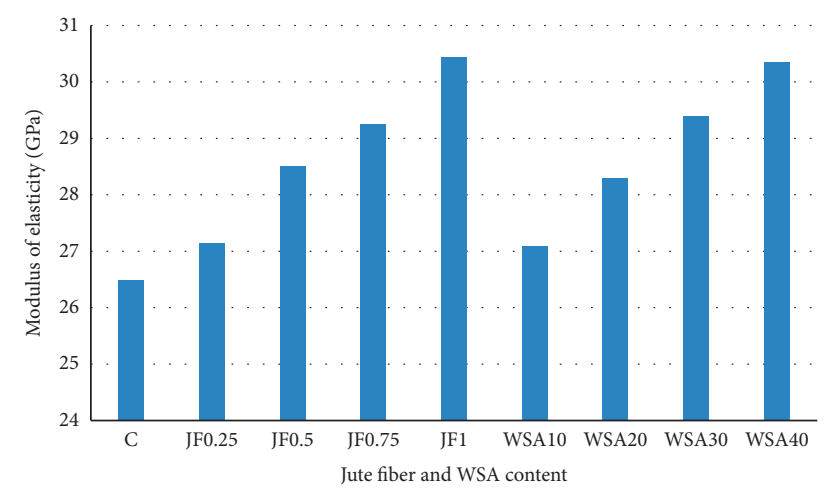

FIgURE 10: Modulus of elasticity of mixture containing jute fiber and WSA.

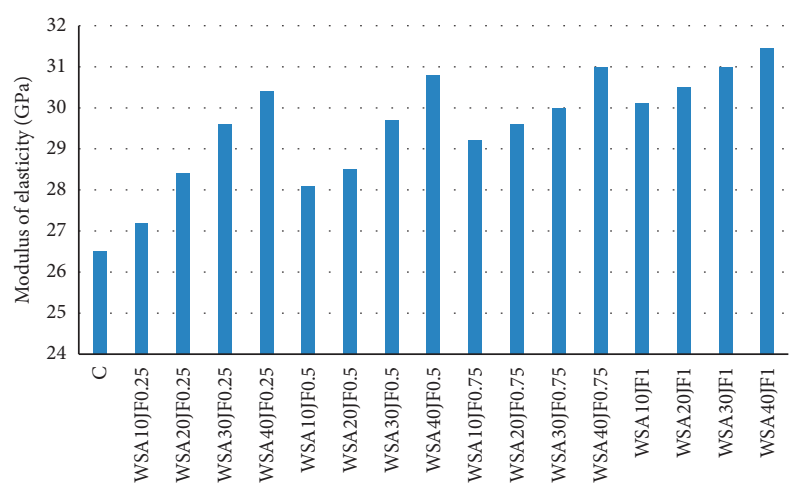

Jute fiber and WSA content

FIGURE 11: Modulus of elasticity of mixture containing jute fiber and WSA.

cementitious component in concrete increases. The same observation was observed by Bheel et al. [50].

3.6. Water Penetration Depth. Figure 12 shows the water penetration depth of concrete containing $0.25 \%$ to $1 \%$ of jute fiber as the reinforcement ingredient at 28 days. The permeability of concrete was estimated as $20 \mathrm{~mm}, 18 \mathrm{~mm}$, $15 \mathrm{~mm}$, and $14 \mathrm{~mm}$ at $0.25 \%, 0.5 \%, 0.75 \%$, and $1 \%$ of jute fiber which is less than that in plain concrete at 28 days,

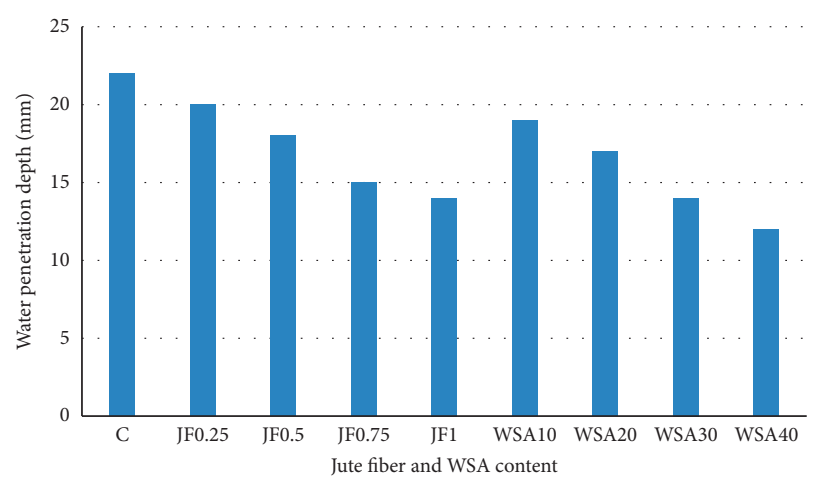

FIgURe 12: Permeability of mixture containing jute fiber and WSA.

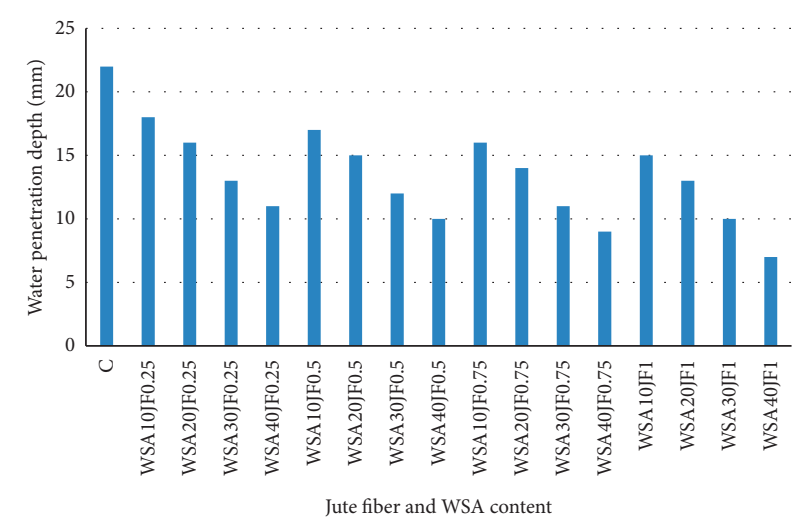

FIgURE 13: Permeability of mixture containing jute fiber and WSA.

respectively. The outcome suggested that the permeability of concrete is reduced with increase in jute fiber utilized as the reinforcement component. The permeability of mixture with the introduction of $10 \%$ to $40 \%$ of WSA as the replacement of sand in concrete at 28 days is shown in Figure 12. The water penetration depth of concrete was recorded as $13.64 \%$, $22.73 \%, 36.36 \%$, and $45.55 \%$ at $10 \%, 20 \%, 30 \%$, and $40 \%$ of WSA as the replacement for sand ingredient which is less when compared to plain concrete at 28 days, respectively. It was recorded that the inclusion of WSA in concrete results in reduction in permeability. This aspect was in agreement with that of Guneyisi et al. [51] that the permeability of concrete is reduced by $29 \%$ while utilizing MK equal to $15 \%$ as the cementitious material at 28 days. Figure 13 shows that the permeability of concrete with the introduction of $0.25 \%$ to $1 \%$ jute fiber and $10 \%$ to $40 \%$ of WSA as the replacement for sand ingredient at 28 days. The maximum water penetration depth was measured as $22 \mathrm{~mm}$ at $0 \%$ of jute fiber along with $0 \%$ of WSA, and the lowest water penetration depth was estimated as $7 \mathrm{~mm}$ while utilizing $1 \%$ of jute fiber along with $40 \%$ of WSA as the replacement for sand ingredient at 28 days, respectively. It was observed that the permeability of concrete was reduced while jute fiber and WSA utilized increase together in concrete. This opinion conforms with that of Bheel et al. [45] that the permeability of concrete was reduced as the extent of metakaolin and GGBFS as the binary cementitious component in concrete increases. 


\section{Conclusions}

In this experimental work, the separate and combined effect of jute fiber as the reinforcement ingredient and WSA as the replacement of sand in concrete was determined to obtain the fresh and hardened properties of concrete. Based on the experimental outcomes, the following key points are drawn:

(i) The slump is recorded as $13.80 \%, 27.58 \%, 37.93 \%$, and $50 \%$ at $0.25 \%, 0.50 \%, 0.75 \%$, and $1 \%$ of jute fiber which is less when compared to concrete without jute fiber. However, the slump is noted as $20.68 \%, 36.21 \%, 50 \%$, and $65.52 \%$ at $10 \%, 20 \%$, $30 \%$, and $40 \%$ of WSA which is lower than that in plain concrete. Moreover, the optimum slump was noted as $58 \mathrm{~mm}$ at $0 \%$ of jute fiber and $0 \%$ of WSA, and the lowest slump is measured as $12 \mathrm{~mm}$ at $1 \%$ of jute fiber and $40 \%$ of WSA as fine aggregate replacement. This result shows that the slump is reduced while the extent of jute fiber and WSA increases in concrete.

(ii) The compressive strength, splitting tensile strength, and flexural strength are improved by $31.5 \mathrm{MPa}, 3.60 \mathrm{MPa}$, and $5 \mathrm{MPa}$, which is $10.14 \%$, $12.50 \%$, and $11.11 \%$ at $0.50 \%$ of jute fiber, higher that that in plain concrete, and the lowest compressive, splitting tensile, and flexural strengths are estimated as $28 \mathrm{MPa}, 3.10 \mathrm{MPa}$, and $4.30 \mathrm{MPa}$, that is, $2.1 \%, 3.1 \%$, and $4.44 \%$, at $1 \%$ of jute fiber as the reinforcement ingredient, lower than in control mix at 28 days, respectively.

(iii) The optimum compressive, splitting tensile, and flexural strengths are recorded as $32 \mathrm{MPa}$, $3.50 \mathrm{MPa}$, and $4.92 \mathrm{MPa}$ at $30 \%$ of WSA, and the minimum strength was calculated as $30.60 \mathrm{MPa}$, $3.35 \mathrm{MPa}$, and $4.70 \mathrm{MPa}$ while utilizing $40 \%$ of WSA as the replacement for sand ingredient in concrete at 28 days correspondingly.

(iv) The optimum compressive, splitting tensile, and flexural strengths are measured as $32.88 \mathrm{MPa}$, $3.80 \mathrm{MPa}$, and $5.30 \mathrm{MPa}$ at $0.50 \%$ of jute fiber along with $30 \%$ of WSA, and the lowest compressive, splitting tensile, and flexural strengths are estimated as $28 \mathrm{MPa}, 3.36 \mathrm{MPa}$, and $4.40 \mathrm{MPa}$ while utilizing $1 \%$ of jute fiber along with $40 \%$ of WSA as the replacement for sand ingredient at 28 days correspondingly. It was observed that the compressive, splitting tensile, and flexural strengths are enhanced while utilizing jute fiber up to $0.50 \%$ and WSA equal to $30 \%$ together and with further addition, they are reduced.

(v) The modulus of elasticity of concrete was measured as $2.45 \%, 7.55 \%, 10.38 \%$, and $14.91 \%$ at $0.25 \%, 0.5 \%, 0.75 \%$, and $1 \%$ of jute fiber which is higher than that in plain concrete at 28 days, respectively. Also, the modulus of elasticity of concrete was recorded as $2.26 \%, 6.79 \%, 10.94 \%$, and $14.53 \%$ at $10 \%, 20 \%, 30 \%$, and $40 \%$ of WSA as the replacement for sand ingredient which is greater than in plain concrete at 28 days correspondingly.

(vi) Additionally, the maximum modulus of elasticity was measured as $31.45 \mathrm{GPa} \mathrm{mm}$ at $1 \%$ of jute fiber along with $40 \%$ of WSA, and the lowest water penetration depth was estimated to be $26.50 \mathrm{GPa}$ while utilizing $0 \%$ of jute fiber along with $0 \%$ of WSA as the replacement for sand ingredient at 28 days, respectively. It was observed that the modulus of elasticity increased while jute fiber and WSA utilized increase together in concrete.

(vii) The permeability of concrete was measured as $9 \%$, $18.18 \%, 31.82 \%$, and $36.40 \%$ at $0.25 \%, 0.5 \%$, $0.75 \%$, and $1 \%$ of jute fiber which is less than in plain concrete at 28 days, respectively. However, the water penetration depth of concrete was recorded as $13.64 \%, 22.73 \%, 36.36 \%$, and $45.55 \%$ at $10 \%, 20 \%, 30 \%$, and $40 \%$ of WSA as the replacement for sand ingredient which is less when compared to plain concrete at 28 days, respectively.

(viii) The maximum water penetration depth was measured as $22 \mathrm{~mm}$ at $0 \%$ of jute fiber along with $0 \%$ of WSA, and the lowest water penetration depth was estimated as $7 \mathrm{~mm}$ while utilizing $1 \%$ of jute fiber along with $40 \%$ of WSA as the replacement for sand ingredient at 28 days, respectively. It was observed that the permeability of concrete was reduced while jute fiber and WSA utilized increase together in concrete.

(ix) On the basis of experimental study, the use of jute fiber up to $0.50 \%$ along with $30 \%$ of WSA as the replacement of sand in concrete is suggested for structural applications.

\section{Data Availability}

The datasets generated during the current study are available from the corresponding author upon request.

\section{Conflicts of Interest}

The authors declare that they have no conflicts of interest.

\section{References}

[1] D.-Y. Yoo, J.-H. Lee, and Y.-S. Yoon, "Effect of fiber content on mechanical and fracture properties of ultra high performance fiber reinforced cementitious composites," Composite Structures, vol. 106, pp. 742-753, 2013.

[2] R. P. Chandramouli, N. Pannirselvam, and T. Sekhar, "Strength properties of glass fibre concrete," Composite Structures, vol. 5, no. 4, pp. 1-7, 2010.

[3] B. Boulekbache, M. Hamrat, M. Chemrouk, and S. Amziane, "Flexural behaviour of steel fibre-reinforced concrete under cyclic loading," Construction and Building Materials, vol. 126, pp. 253-262, 2016. 
[4] A. M. Brandt, "Fibre reinforced cement-based (FRC) composites after over 40 years of development in building and civil engineering," Composite Structures, vol. 86, no. 1-3, pp. 3-9, 2008.

[5] S. H. Kosmatka, B. Kerkhoff, and W. C. Panarese, Design and Control of Concretemixtures, Portland Cement Association (PCA), Skokie Illinois, IL, USA, 4th edition, 2011.

[6] M. S. Islam, "Simplified shear-strength prediction models for steel-fibre-reinforced concrete beams," Proceedings of the Institution of Civil Engineers-Construction Materials, vol. 86, pp. 1-13, 2018.

[7] M. S. Islam and S. Alam, "Principal component and multiple regression analysis for steel fiber reinforced concrete (SFRC) beams," International Journal of Concrete Structures and Materials, vol. 7, no. 4, pp. 303-317, 2013.

[8] R. Sethunarayanan and S. Chockalingam, "Natural fiber reinforced concrete," International Journal of Concrete Structures and Materials, vol. 5, pp. 57-60, 1989.

[9] O. Onuaguluchi and N. Banthia, "Plant-based natural fibre reinforced cement composites: a review," Cement and Concrete Composites, vol. 68, pp. 96-108, 2016.

[10] K. L. Pickering, M. G. A. Efendy, and T. M. Le, "A review of recent developments in natural fibre composites and their mechanical performance," Composites Part A: Applied Science and Manufacturing, vol. 83, pp. 98-112, 2016.

[11] A. Gopinath, M. S. Kumar, and A. Elayaperumal, "Experimental investigations on mechanical properties of jute fiber reinforced composites with polyester and epoxy resin matrices," Procedia Engineering, vol. 97, pp. 2052-2063, 2014.

[12] L. Yan, N. Chouw, L. Huang, and B. Kasal, "Effect of alkali treatment on microstructure and mechanical properties of coir fibres, coir fibre reinforced-polymer composites and reinforced-cementitious composites," Construction and Building Materials, vol. 112, pp. 168-182, 2016.

[13] M. A. Aziz, P. Paramasivam, and S. L. Lee, "Prospects for natural fibre reinforced concretes in construction," International Journal of Cement Composites and Lightweight Concrete, vol. 3, no. 2, pp. 123-132, 1981.

[14] G. Ramakrishna and T. Sundararajan, "Impact strength of a few natural fibre reinforced cement mortar slabs: a comparative study," Cement and Concrete Composites, vol. 27, no. 5, pp. 547-553, 2005.

[15] M. Zakaria, M. Ahmed, M. M. Hoque, and A. Hannan, "Effect of jute yarn on the mechanical behavior of concrete composites," SpringerPlus, vol. 4, no. 1, p. 731, 2015.

[16] Z. Li, L. Wang, and X. Wang, "Compressive and flexural properties of hemp fiber reinforced concrete," Fibers and Polymers, vol. 5, no. 3, pp. 187-197, 2004.

[17] M. M. Hossain and F. Abdulla, "Jute production in Bangladesh: a time series analysis," Journal of Mathematics and Statistics, vol. 11, no. 3, pp. 93-98, 2015.

[18] M. S. Islam and S. J. Ahmed, "Influence of jute fiber on concrete properties," Construction and Building Materials, vol. 189, pp. 768-776, 2018.

[19] E. M. R. Fairbairn, B. B. Americano, G. C. Cordeiro, T. P. Paula, R. D. Toledo Filho, and M. M. Silvoso, "Cement replacement by sugar cane bagasse ash: $\mathrm{CO} 2$ emissions reduction and potential for carbon credits," Journal of Environmental Management, vol. 91, no. 9, pp. 1864-1871, 2010.

[20] X. Pan and Y. Sano, "Fractionation of wheat straw by atmospheric acetic acid process," Bioresource Technology, vol. 91, 2005.

[21] H. Biricik, F. Aköz, I. Berktay, and A. N. Tulgar, "Study of pozzolanic properties of wheat straw ash," Cement and Concrete Research, vol. 91, 1999.
[22] N. M. Al-Akhras and B. A. Abu-Alfoul, "Efect of wheat straw ash on mechanical properties of autoclaved mortar," Cement and Concrete Research, vol. 91, 2002.

[23] A. Qudoos, H. G. Kim, B. Atta-ur-Rehman, and J. S. Ryou, "Efect of mechanical processing on the pozzolanic efciency and the microstructure development of wheat straw ash blended cement composites," Construction and Building Materials, vol. 5, p. 545, 2018.

[24] ASTM, Standard Specification for Coal Fly Ash and Raw or Calcined Natural Pozzolan for Use in Concrete, C618, West Conshohocken, PA, USA, 2008.

[25] ASTM, Standard Test Method for Sieve Analysis of Fine and Coarseaggregates, American Society for Testing Materials, Philadelphia, PA, USA, 2005.

[26] ASTM, Standard test Method for Bulk Density ("Unit Weight") and Voids in Aggregate, Annual Book of ASTM Standards, Philadelphia, PA, USA, 1997.

[27] ASTM C128, Standard Method of Test for Specific Gravity and Water Absorptionof Fine Aggregate, American Society for Testing Materials, West Conshohocken, PA, USA, 1993.

[28] ASTM C127, Standard Method of Test for Specific Gravity and Water Absorptionof Coarse Aggregate, American Society for Testing Materials, Philadelphia, PA, USA, 1993.

[29] Standard, "Standard test method for slump of hydraulic cementconcrete," Annual book of ASTM Standards, vol. 4, 1991.

[30] Standard, "Standard test method for compressive strength ofConcrete specimens," Annual Book of ASTM Standards, vol. 9, 2015.

[31] ASTM, "Test for Splitting Tensile Strength of Cylindrical Concretespecimens," 1990.

[32] ASTM, Standard Test Method for Flexural Strength of Concrete (UsingSimple Beam with Center-Point Loading), ASTM International, West Conshohocken, PA, USA, 2008.

[33] ASTM C469, "Standard test method for static modulusof elasticity and Poisson's ratio of concrete in compression," Annual Book of ASTM Standards, West Conshohocken, PA, USA, 2014.

[34] British Standard Institution, BS EN 12390-8: Testing HardenedConcrete: Part 8: Depth of Penetration of Water under Pressure, BSI, London, UK, 2009.

[35] N. Bheel, P. Awoyera, O. Aluko, S. Mahro, A. Viloria, and C. A. S. Sierra, "Sustainable composite development: novel use of human hair as fiber in concrete," Case Studies in Construction Materials, vol. 13, 2020.

[36] N. Bheel, M. H. W. Ibrahim, A. Adesina, C. Kennedy, and I. A. Shar, "Mechanical performance of concrete incorporating wheat straw ash as partial replacement of cement," Journal of Building Pathology and Rehabilitation, vol. 6, no. 1, pp. 1-7, 2020.

[37] N. Bheel, M. A. Jokhio, J. A. Abbasi, H. B. Lashari, M. I. Qureshi, and A. S. Qureshi, "Rice husk ash and fly ash effects on the mechanical properties of concrete," Engineering, Technology \& Applied Science Research, vol. 10, no. 2, pp. 5402-5405, 2020.

[38] A. A. Dayo, A. Kumar, A. Raja, N. Bheel, and Z. H. Shaikh, "Use of sugarcane bagasse ash as a fine aggregate in cement concrete," Engineering Science and Technology International Research Journal, vol. 3, no. 3, pp. 8-11, 2019.

[39] M. A. Keerio, S. A. Abbasi, A. Kumar, N. Bheel, K. ur Rehaman, and M. Tashfeen, "Effect of silica fume as cementitious material and waste glass as fine aggregate replacement constituent on selected properties of concrete," 2020.

[40] M. Zakaria, M. Ahmed, M. M. Hoque, and S. Islam, "Scope of using jute fiber for thereinforcement of concrete material," 
Engineering Science and Technology International Research Journal, vol. 2, no. 11, pp. 1-11, 2017.

[41] P. Kanaka and B. Thiyagarajan, "Experimental study on partial replacement of fine aggregate with glass waste," International Journal for Scientific Research \& Development, vol. 5, no. 2, 2017.

[42] M. N. Bajad, C. D. Modhera, and A. K. Desai, "Effect of glass on strength of concrete subjected to sulphate attack," International Journal of Civil Engineering Research and Development (IJCERD), vol. 1, no. 2, pp. 1-13, 2011.

[43] L. Yan and N. Chouw, "Natural FRP tube confined fibre reinforced concrete under pure axial compression: a comparison with glass/carbon FRP," Thin-Walled Structures, vol. 82, pp. 159-169, 2014.

[44] E. Mello, C. Ribellato, and E. Mohamedelhassan, "Improving concrete properties with fibers addition," International Journal of Civil and Environmental Engineering, vol. 8, no. 3, pp. 249-254, 2014.

[45] N. Bheel, S. A. Abbasi, P. Awoyera et al., "Fresh and hardened properties of concrete incorporating binary blend of metakaolin and ground granulated blast furnace slag as supplementary cementitious material," Advances in Civil Engineering, vol. 2020, 2020.

[46] N. Bheel and A. Adesina, "Influence of binary blend of corn cob ash and glass powder as partial replacement of cement in concrete," 2020.

[47] A. A. Dayo, A. Kumar, A. Raja, N. Bheel, A. W. Abro, and Z. H. Shaikh, "Effect of sugarcane bagasse ash as fine aggregates on the flexural strength of concrete," 2019.

[48] N. Bheel, F. A. Memon, and S. L. Meghwar, "Study of fresh and hardened properties of concrete using cement with modified blend of millet husk ash as secondary cementitious," 2020.

[49] K. Y. Foong, U. J. Alengaram, M. Z. Jumaat, and K. H. Mo, "Enhancement of the mechanical properties of lightweight oil palm shell concrete using rice husk ash and manufactured sand," 2015.

[50] N. Bheel, S. K. Mahro, and A. Adesina, "Influence of coconut shell ash on workability, mechanical properties, and embodied carbon of concrete," Environmental Science and Pollution Research, vol. 34, pp. 1-11, 2020.

[51] E. Güneyisi, M. Gesoğlu, S. Karaoğlu, and K. Mermerdaş, "Strength, permeability and shrinkage cracking of silica fume and metakaolin concretes," Construction and Building $\mathrm{Ma}$ terials, vol. 34, pp. 120-130, 2012. 